\title{
Una "Toledo Extremeña". Contribución del Servicio de Ordenación de Ciudades Históricas a la monumentalización de Trujillo (Cáceres) durante el desarrollismo franquista
}

\author{
An "Extremaduran Toledo". The contribution of the Historical \\ Towns Planning Service to the monumentalization of Trujillo \\ (Cáceres) at the time of Franco's developmental policies
}

María Antonia PARDO FERNÁNDEZ

Universidad de Extremadura

RESUMEN: Al incremento notable del número de declaraciones de conjuntos históricos que se produjo en la década de los sesenta sucedió una importante labor de restauración monumental durante ese decenio y el siguiente, y fruto de ello fue la transformación de numerosas poblaciones españolas reconocidas como conjuntos histórico- artísticos. Una actividad restauradora de la que se encargaron la Dirección General de Bellas Artes del Ministerio de Educación Nacional y también la Dirección General de Arquitectura del Ministerio de Vivienda, desarrollando esta última una importante labor de recuperación arquitectónica desde su Servicio de Ordenación de Ciudades Históricas. Ambos organismos fueron los responsables del establecimiento de la imagen actual de buena parte de los conjuntos histórico-artísticos españoles, valiéndose para ello de criterios muy similares heredados del período anterior.

Palabras clave: Restauración monumental, Desarrollismo franquista, Conjuntos Históricos, Dirección General de Arquitectura, Extremadura, Trujillo.

ABSTRACT: The 1960s witnessed an outstanding increase in the amount of historical-artistic complex declarations in Spain. This was followed by a large institutional effort concerning monument restoration both in that decade and the next, which in turn brought about important changes in the many Spanish towns that were declared as historical-artistic complexes then. Two institutions were the main agents of this restoration process: the Dirección General de Bellas Artes del Ministerio de Educación Nacional (General Bureau for Fine Arts, a section of the Ministry of National Education) and the Dirección General de Arquitectura del Ministerio de Vivienda (General Bureau for Architectural Affairs, a section of the Ministry of Housing). One sub-section of the latter, that of Ordenación de Ciudades Históricas (Historical Towns Planning), was responsible for this far-reaching policy of architectural recovery. These official agencies established the present-day image of many Spanish historical-artistic complexes, for which labour they used rather similar criteria to those employed in the previous period.

Keywords: Monumental restoration, Franco's developmental policies, Historical-artistic complexes, General Bureau of Architecture, Extremadura, Trujillo, Spain 


\section{ANTECEDENTES}

Las actuaciones que desarrollara la Dirección General de Bellas Artes sobre la arquitectura histórica a lo largo del período franquista en que el territorio español se dividió en distintas zonas ${ }^{1}$, estuvieron marcadas por una serie de características comunes $^{2}$. Para el caso extremeño y el período comprendido entre 1940 y 1958, conocido como "primer franquismo", se encuentran recogidas en una interesante publicación ${ }^{3}$ aunque cabe señalar también otros estudios que abordan parcialmente las restauraciones del período siguiente, conocido como "desarrollismo" (1959-1975), concretamente en la provincia de Badajoz

\footnotetext{
${ }^{1}$ El presente artículo se ha elaborado en el marco de los proyectos de investigación "Los Arquitectos Restauradores en la España del Franquismo. De la continuidad de la Ley de 1933 a la recepción de la teoría europea". Referencia: HAR2015-68109-P, financiado por el Ministerio de Economía y Competitividad y Fondos Feder; y "Cartografía de la restauración monumental en Extremadura durante el periodo del desarrollismo franquista (1959-1975)". Referencia IB16130, financiado por la Consejería de Economía e Infraestructuras de la Junta de Extremadura y Fondos Feder.

2 Entre los trabajos más recientes que abordan el análisis de estas intervenciones destacamos $\mathrm{M}$. P. GARCÍA CUETOS, E. ALMARCHA NÚÑEZHERRADOR y A. HERNÁNDEZ MARTÍNEZ (coords), España Italia ante la recuperación monumental de posguerra, Gijón, 2010; ÍDEM, Historia, restauración y reconstrucción monumental en la posguerra española, Madrid, 2012.
}

${ }^{3} \mathrm{Al}$ respecto consultar M. P. MOGOLLÓN CANOCORTÉS, La restauración monumental durante la posguerra en Extremadura y la Dirección General de Bellas Artes 19401958, Cáceres, 2011; ÍDEM, “La fiel restauración en las intervenciones de González Valcárcel: aproximación a la práctica restauradora del arquitecto en la España franquista", en J. DELGADO RODRIGUES (coord.), De Viollet le Duc a Carta de Veneza, Lisboa, 2014, pp. 4754; ÍDEM, "La fachada del santuario del Monasterio de Guadalupe y su restauración", en M.A. ZALAMA RODRIGUEZ y M. P. MOGOLLÓN CANO-CORTÉS, Alma Ars. Estudios de arte e iconografía en homenaje al Dr. Salvador Andrés Ordax, Valladolid 2013, pp. 335-340.

4 M. A. PARDO FERNÁNDEZ, Un siglo de restauración monumental en los conjuntos históricos declarados de la provincia de Badajoz: 1900-2000, Cáceres, 2007; ÍDEM, “El arquitecto José Menéndez-Pidal y sus criterios de restauración monumental sobre los
Las características de esas actuaciones que se desarrollaron durante la posguerra y la década de los cincuenta, y que constituyen los antecedentes inmediatos de las obras que aquí se van a analizar, se produjeron en su mayoría exclusivamente sobre edificios monumentales, de los cuales, los más significativos, habían quedado amparados legalmente tras la declaración masiva de $1931^{5}$. En ella se reconocieron como monumentos alrededor de ochocientos inmuebles distribuidos por todo el territorio nacional, correspondiendo poco más de una treintena al ámbito extremeño. No hubo muchas declaraciones de conjuntos histórico-artísticos porque la legislación de estos momentos no recogía una conceptualización y definición de los mismos como tales.

En el caso de Extremadura, no todas las declaraciones realizadas hasta comienzos del "desarrollismo" correspondieron a la figura tutelar de monumento, pues Guadalupe será reconocido como conjunto históricoartístico en 1943, Cáceres en 1949, Plasencia en 1958 y Cuacos de Yuste (como Sitio Histórico) en 1959. En la provincia de Badajoz, en este período previo al "desarrollismo", no se producirán declaraciones de conjuntos históricos-artísticos. Estas habrían de esperar hasta la década de los sesenta.

En consecuencia, los protagonistas de la práctica restauradora de este primer período franquista serán los monumentos, siendo los monasterios de Yuste y Guadalupe, en la provincia de Cáceres, los más intervenidos hasta 1959; al tiempo que en la provincia de

conjuntos histórico-artísticos", Laboratorio de Arte, XXV, 2013, pp. 799-816; ÍDEM, “La ambientación de la ciudad histórica. Restauración monumental y urbana en los años sesenta", en M.A. ZALAMA RODRIGUEZ y M. P. MOGOLLÓN CANO-CORTÉS, Op.cit., pp. 341346; ÍDEM, "En dignas condiciones de presentación. José Menéndez-Pidal y la práctica de la restauración monumental en castillos y fortalezas de Extremadura", en J. DELGADO RODRIGUES (coord.), Op.cit., pp. 3946.

5 Decreto de 3 de Junio de 1931, Ministerio de Instrucción Pública, publicado en la Gaceta de Madrid, no 155 de 4 de Junio de 1931. 
Badajoz y en este mismo período serán las ruinas emeritenses, protegidas desde 1913, y algunos monumentos de la capital de provincia, los que reciban atención por parte de la Dirección General de Bellas Artes, entre ellos la alcazaba y la catedral de Badajoz.

En ambas provincias, los monumentos señalados habían sido reconocidos por su importante valor histórico principalmente y artístico, además de por la carga simbólicoideológica que para el régimen franquista suponían dichas declaraciones y sus restauraciones posteriores. Una política restauradora que afectaría por igual tanto a los monumentos como a los conjuntos, a los que trataría con los mismos criterios de intervención que a los primeros ${ }^{6}$.

Existirá un interés extraordinario por el aspecto exterior de los edificios, por la epidermis de una arquitectura con un valor histórico-artístico incuestionable pero que es reinterpretado y alterado en la práctica restauradora a partir de unos criterios plenamente asumidos al comenzar la etapa desarrollista. En definitiva, en el intento por solucionar los problemas físicos y estructurales de las fábricas históricas en aquel momento se "rediseñará", se modificará paulatinamente, la imagen de un buen número de monumentos y conjuntos del patrimonio arquitectónico español a la que debemos mucho en la actualidad, pues se desarrolló una política restauradora a base de actuaciones continuas, precisas, con criterios de intervención homogéneos y uniformes que irá progresivamente alterando la imagen de los inmuebles. Así había ocurrido en la primera etapa del régimen franquista y así habría de continuar

${ }^{6}$ Los principales problemas constructivos que presentaban estos monumentos eran generalmente estructurales, en fábricas y cubiertas principalmente, por lo que para solucionarlos los arquitectos de zona se servirán de las técnicas más modernas entonces capaces de garantizar la solidez de aquellas -recurriendo con frecuencia al hormigón armado-. En cuanto a su acabado final lo habitual será recurrir a materiales y técnicas tradicionales que devuelvan el aspecto original al monumento desde la perspectiva de un peculiar concepto de autenticidad. sucediendo en la segunda, afectando tanto a monumentos como a conjuntos (estos cada vez en mayor número), se trate de obras auspiciadas desde la Dirección General de Bellas Artes o desde la Dirección General de Arquitectura.

\section{DEL MONUMENTO AL CONJUNTO: LA DIRECCIÓN GENERAL DE AR- QUITECTURA EN EXTREMADURA}

Resulta muy significativo el incremento de declaraciones de conjuntos monumentales que se produce en la década de los sesenta y de manera especialmente más intensa en la de los setenta. De hecho, del total de conjuntos declarados en las cuatro décadas de gobierno franquista sólo un $6.2 \%$ de las declaraciones se produjeron en la década de los cuarenta, disminuyendo a un $4.8 \%$ en la de los cincuenta, para incrementarse un 36.5 $\%$ en la de los sesenta y un $52.4 \%$ en la de los setenta ${ }^{7}$.

Este fue un proceso que afectó a toda España y así en la década de los sesenta, la hoy comunidad autónoma de Castilla y León contaba con el mayor número de declaraciones (16), seguida muy de cerca por otras autonomías como Andalucía (14), Aragón y la actual Comunidad Valenciana (8), Castilla la Mancha y Extremadura (6) ${ }^{8}$.

Sin embargo, el reconocimiento de dichos conjuntos no vino acompañado de una conceptualización y definición de esta figura tutelar. Entonces, el conjunto históricoartístico se definía como una agrupación de monumentos de valor histórico, artístico y pintoresco ${ }^{9}$ al que se trataba, en el campo de la práctica restauradora, como al monumen-

\footnotetext{
${ }^{7}$ Estadística propia a partir de los datos extraídos del Mapa del Patrimonio Histórico Inmueble, Tomo I-Bienes de Interés Cultural, Madrid, 1995.

${ }^{8}$ Ibídem.

${ }^{9}$ Ley de 13 de mayo de 1933 sobre defensa, conservación y acrecentamiento del Patrimonio Histórico Artístico Nacional publicada en la Gaceta de Madrid, no 145 de 25 de Mayo de 1933. Título Primero, Artículo 33.
} 
to ${ }^{10}$. Habría que esperar hasta mediados de los sesenta a que la normativa incorporase aspectos de carácter urbanístico y a que en los proyectos y la política de restauración monumental del Estado se asumiera la existencia de aquellos ${ }^{11}$.

El hecho de contar con una legislación conservacionista y monumentalista, como la define Castillo Ruiz ${ }^{12}$, reforzó legalmente la utilización de unos criterios de restauración que no tardaron en proyectarse sobre los monumentos por parte de la Dirección General de Bellas Artes, al poco de ser estos declarados. A las declaraciones le seguían de inmediato las intervenciones, dando lugar a un tratamiento muy similar en los conjuntos que el que se había dado a los monumentos. Es decir, a la monumentalización de unos espacios en donde el monumento en su individualidad seguía teniendo un fuerte protagonismo, pero en el que los espacios abiertos (plazas, plazuelas) y enclaves o hitos urbanos significativos (tales como fortalezas y recintos amurallados) también iban a ser tratados como monumentales espacios urbanos ${ }^{13}$.

${ }^{10}$ C. BARRERO RODRÍGUEZ, La ordenación jurídica del patrimonio histórico, Madrid, 1990.

${ }^{11}$ Instrucciones para la defensa de los conjuntos histórico artísticos. Política de principios para la protección de las antiguas ciudades españolas, Ministerio de Educación Nacional, Dirección General de Bellas Artes, Servicio de Defensa del Patrimonio Artístico Nacional, 1964.

12 J. CASTILLO RUIZ, El entorno de los bienes inmuebles de interés cultural, Granada, 1997.

${ }^{13}$ Ordóñez Vergara describe todo el proceso de restauración llevado a cabo en la alcazaba malagueña vinculándolo con la situación nacional cuyos criterios de intervención sintetiza claramente y en los que se intuye el tratamiento que más adelante se dará a los conjuntos: "monumentalismo, con el que se pretende la conquista del paisaje y del entorno del monumento a través de su magnitud, la significación de sus dimensiones $\mathrm{y}$, especialmente, gracias a la altura hasta la que se recrecen las fábricas renovadas, muchas veces caprichosamente y al margen de evidencia histórica alguna; perfecto acabado...; imagen de conjunto, donde se evite o disimule toda discontinuidad, aun las históricas". J. ORDOÑEZ VERGARA, "Restauración arquitectónica en la autarquía. La alcazaba de Málaga: entre la reconstrucción nacional y la escenografía historicista", en I. HENARES CUÉLLAR, J. CASTILLO
En este contexto es cuando comienza sus actuaciones la Dirección General de Arquitectura dependiente del Ministerio de la Vivienda y en concreto su Sección de Ordenación de Ciudades Histórico Artísti$\operatorname{cas}^{14}$ que no tardará en ocuparse de la plaza mayor de Trujillo. Al frente de la misma estuvieron profesionales que también habían trabajado para la Dirección General de Bellas Artes, por lo que la conexión entre una y otra, en lo que a criterios de intervención se refiere, era evidente. Tal fue el caso de D. Francisco Pons Sorolla o de D. José Manuel González Valcárcel, este último arquitecto de zona en la provincia cacereña y responsable directo de las obras que se llevarán a cabo para la monumentalización del conjunto histórico trujillano.

Cabe destacar, además de lo anterior, la dilatada trayectoria de este organismo en el tiempo (pues desaparece en 1985 tras treinta y cinco años dedicado a esta tarea de ambientación histórica) y su importante labor en lo que Peris Sánchez también considera "el comienzo de la recuperación de las ciudades históricas, inicialmente entendidas más en el contexto de los grandes edificios monumen-

RUIZ, G. PÉREZ ZALDUONDO y M. I. CABRERA GARCÍA (coords), Dos décadas de cultura artística en el Franquismo (1936-1956), Granada, 2001, pp. 587-615.

${ }^{14}$ La Sección de Ciudades de Interés Artístico Nacional fue "creada en 1950 por el Ministerio de la Gobernación para atender los valores de la arquitectura urbana y popular. Su creación constituyó un punto de mira novedoso ante al que hasta entonces venía centrando la atención de los restauradores estatales". A. HERNÁNDEZ MARTÍNEZ y B. CASTRO FERNÁNDEZ, "Patrimonio monumental y turismo. La ordenación de conjuntos monumentales en Aragón: el caso de Sos del Rey Católico (Zaragoza)", e-rph, no 13, 2013, p. 9. “En 1950 el Jefe de Ciudades Artísticas era Rodolfo García de Pablos al que sucedió en 1951 Francisco Pons Sorolla...A partir de 1958 la sección de Ordenación de Ciudades de Interés Artístico Nacional realiza tareas en entornos monumentales y en algunos edificios...". D. PERIS SÁNCHEZ, "Del monumento al patrimonio histórico. Caminos de la segunda mitad del siglo XX", en M. P. GARCÍA CUETOS, E. ALMARCHA NÚÑEZ-HERRADOR y A. HERNÁNDEZ MARTÍNEZ (coords.), Historia, restauración y reconstrucción monumental..., p. 453. 
tales y con un carácter ambientalista en las recuperaciones realizadas pero con tratamientos de pavimentaciones y acondicionamiento del entorno de calidad"15.

En Extremadura, la Dirección General de Arquitectura intervendrá desde 1953, poco después del inicio de su actividad, y hasta comienzos de la década de los ochenta (1981). Según lo recogido en el Inventario de expedientes de restauración de edificios y ordenación de conjuntos monumentales la primera de sus actuaciones tuvo lugar en la plaza de Guadalupe finalizando con las obras del entorno de la Iglesia de la Granada en Llerena (Badajoz) ${ }^{16}$.

No hay constancia de intervenciones de la Dirección General de Arquitectura en la provincia badajocense con anterioridad a la década de los sesenta debido, como señalábamos al comienzo, a la inexistencia de declaraciones de conjuntos históricos-artísticos, mientras que en su homóloga cacereña, además de Guadalupe (primer conjunto reconocido en Extremadura) intervendrá en Cáceres, Trujillo y Plasencia, todos ellos con tal consideración desde 1949, 1958 y 1961 respectivamente $^{17}$.

Cuando se produzcan las primeras declaraciones en la provincia de Badajoz, sólo Zafra, Llerena y Jerez de los Caballeros (es decir tres de los cinco conjuntos que se declaran en esta provincia) serán los lugares en los que intervenga la Dirección General de Arquitectura $^{18}$.

${ }^{15}$ M. P. GARCíA CUETOS, E. ALMARCHA NÚÑEZ-HERRADOR y A. HERNÁNDEZ MARTÍNEZ (coords.), Historia, restauración y reconstrucción monumental..., p. 454.

${ }^{16}$ Archivo General de la Administración del Estado (en adelante AGA), Fondo Obras Públicas, Fichero 12/12, Base de datos del Ministerio de la Vivienda 117_004.

${ }_{17}$ También lo hará en las localidades de Pedroso de Acim y Alcántara pero sobre monumentos y no espacios urbanos. S. CASES GÓMEZ DE OLMEDO, Fuentes documentales para el estudio de la restauración de monumentos en España, Madrid, 1989.

${ }^{18}$ Zafra fue reconocida como Conjunto Histórico Artístico en 1965 y tanto Llerena como Jerez de los
En cualquiera de las provincias las intervenciones del período desarrollista responderán a las coordenadas ideológicas nacionalistas ya aludidas pero también a otras premisas que irrumpen con fuerza en estos momentos (como las de la promoción turística $)^{19}$, aunque los criterios de actuación sigan siendo muy similares.

\section{EL TRATAMIENTO DE PLAZAS MA- YORES, PLAZUELAS Y ENTORNOS MONUMENTALES}

La práctica totalidad de los proyectos que la Dirección General de Arquitectura lleve a cabo en Extremadura a lo largo de su existencia desde la Sección y posterior Servicio de Ordenación de Ciudades Históricas, se ocupará de espacios urbanos de fuerte preeminencia visual y peso histórico en el perfil y tramas urbanas de estas ciudades. Es el caso por ejemplo de las plazas mayores de Guadalupe, Cáceres, Trujillo o Llerena así como las denominadas Plazas Grande y Chica de Zafra.

De la documentación cotejada parece observarse una dualidad en el objeto a intervenir. De un lado los espacios abiertos que suelen preceder a monumentos muy significativos en estos conjuntos históricos, configurando plazas o plazuelas tales como las de Santo Domingo en Plasencia o San Miguel en Jerez de los Caballeros, constituyendo un soporte ambiental fundamental pero subordinado al monumento (que es quien realmente posee el valor e interés histórico artístico), es decir, el entorno construido del monumento en cuestión.

Caballeros lo fueron en 1966. Decreto 1505/1965 de 20 de mayo de 1961, Boletín Oficial del Estado, no 136 de 8 de junio de 1965 y Decreto 3301/1966 de 29 de diciembre de 1966, Boletín Oficial del Estado, no 20 de 24 de enero de 1967, respectivamente.

${ }^{19} \mathrm{Al}$ respecto consultar N. TORRES CAMACHO, "Suiza en la aventura de la Mancha: patrimonio y turismo cultural en los años del desarrollismo español", Cuadernos de Turismo, $\mathrm{n}^{\circ}$ 35, 2015, pp. 399-423 y A. MORENO GARRIDO, Historia del turismo en España en el siglo XX, Madrid, 2010. 
Y de otro lado aquellos espacios abiertos con valor propio, histórico-artístico, que rivalizan en protagonismo con los monumentos más importantes del conjunto y que consideramos que son tratados como tales, como monumentales espacios urbanos. Así sucede con la plaza mayor de Llerena y las de Zafra, Cáceres, Trujillo y Guadalupe. En estos que denominamos monumentales espacios urbanos las actuaciones de la Dirección General de Arquitectura no van a variar, en lo que a criterios se refiere, con respecto a las que el mismo organismo realice en los espacios subordinados a grandes monumentos; $y$ a su vez tampoco cambiarán mucho con respecto a las escasas intervenciones que la Dirección General de Bellas Artes lleve a cabo, en un número muy reducido, sobre la trama urbana de algunos conjuntos. De lo que se trata es de alcanzar una escenografía artística que no tiene por qué responder a criterios de autenticidad histórica ${ }^{20}$.

La legislación de referencia por la que se rigen estas actuaciones será la de 193321, la cual se va completando paulatinamente con otras sucesivas, como la contenida en el Decreto de 22 de Julio de $1958^{22}$, y las conocidas como Instrucciones para la defensa de los conjuntos histórico artísticos auspiciadas por la Dirección General de Bellas Artes ${ }^{23}$. "Unas instrucciones o condiciones concretas

${ }^{20}$ M. P. GARCÍA CUETOS, “La Imperial Tarraco. Restauración de los testimonios de la Tarragona romana bajo el franquismo", De Arte. Revista de Historia del Arte, no 13, 2014, pp. 263-286; E. ALMARCHA NÚÑEZHERRADOR, "Recuperar la esencia. El Corral de Comedias y Almagro", en P. MARTÍNEZ-BURGOS GARCÍA y M. E. SAÍNZ MAGAÑA (coords.), El Greco en su IV Centenario: patrimonio hispánico y diálogo intercultural, Toledo, 2016, pp. 377-400.

${ }^{21}$ Ley de 13 de mayo de 1933 relativa al Patrimonio Artístico Nacional, Gaceta de Madrid, nº 145, de 25 de mayo de 1933.

${ }^{22}$ Decreto de 22 de julio de 1958 sobre monumentos provinciales y locales, Boletín Oficial del Estado, nº 193, 13 de agosto de 1958.

${ }^{23}$ J. CASTILLO RUIZ, "Las instrucciones para la defensa de los conjuntos histórico-artísticos: el inicio de la moderna protección de la ciudad histórica en nuestro país", Cuadernos de Arte, no 27, 1996, p. 241. [que como señala Castillo] merecen un papel destacado en la evolución histórica de la tutela del Patrimonio Histórico en nuestro país ya que...son el resultado de un proceso de elaboración teórica-proyectual...para la conceptualización e intervención en las poblaciones de carácter histórico...que debe valorarse como una de las más importantes aportaciones en relación a la integración del patrimonio arquitectónico en su contexto urbano y territorial y al desarrollo de los instrumentos para su regulación" 24 .

La aplicación práctica de esta normativa fue reducida, y para el caso de las actuaciones que analizamos en Trujillo aún no estaba en vigor. Es más, ni siquiera se había producido la declaración de Trujillo como conjunto histórico-artístico en el momento en que comienzan las obras de remodelación de la plaza, cuando lo habitual era restaurar de forma inmediata una vez declarado el monumento o conjunto en cuestión. Estas dos circunstancias reforzaron el mantenimiento de una práctica restauradora sobre los conjuntos igual o muy cercana a la desarrollada en los monumentos por la Dirección General de Bellas Artes aunque desde la Dirección General de Arquitectura también se llevarán a cabo, tímidamente, algunas tareas de reordenación del espacio desde una perspectiva, podríamos considerar, más próxima al ámbito de lo urbanístico.

En definitiva, los criterios que se emplearán responden a la concepción legal que del término monumento se tiene en ese momento y a la ampliación que de dicho concepto se recogerá en la Carta de Venecia, en el sentido teórico ${ }^{25}$, pues no se han estudiado

\footnotetext{
${ }^{24}$ Ibídem, p. 242.

25 “La noción de monumento histórico comprende tanto la creación arquitectónica aislada, como el ambiente urbano o paisajístico que constituya el testimonio de una civilización particular, de una evolución significativa o de un acontecimiento histórico. Esta noción se aplica no sólo a las grandes obras, sino también a las obras modestas que con el tiempo hayan adquirido un significado cultural". "Los ambientes monumentales deben ser objeto de cuidados especiales a fin de salvaguardar su integridad y asegurar su
} 
aún las conexiones entre dicho documento y la práctica restauradora franquista a lo largo de la década de los sesenta. Se ha observado que esos criterios son los que priman en las numerosas declaraciones realizadas de conjuntos monumentales, pudiendo vincularse este hecho con esa evolución conceptual a la que nos referíamos y que, no obstante, está más en relación con la definición del concepto de entorno que con la de conjunto histórico-artístico.

\section{LA DIRECCIÓN GENERAL DE BE- LLAS ARTES Y LAS RESTAURACIO- NES MONUMENTALES EN TRUJI- LLO DURANTE EL PRIMER FRAN- QUISMO}

Los esfuerzos porque en la administración central se tuviera constancia de la importancia histórico artística de Trujillo y se procediese a su declaración como conjunto histórico-artístico comenzaron casi veinte años antes de su declaración como tal. De hecho, ya en 1942, en un escrito dirigido por el Comisario General del Servicio de Defensa del Patrimonio Artístico Nacional al Director General de Bellas Artes del Ministerio de Educación Nacional, se sugiere que junto a Santa María, de la cual se había incoado expediente de declaración, tanto la Plaza como la zona de la Villa Adentro sean también objeto de reconocimiento ${ }^{26}$.

saneamiento, su utilización y su valoración. Los trabajos de conservación y restauración, que se efectúen en ellos, deben inspirarse en los principios enunciados en los artículos precedentes" [referidos al monumento]. Carta de Venecia, artículos 1 y 14 (traducción realizada por María José Martínez Justicia a partir del texto italiano), consultado el 26 junio 2017. URL: http://www.ipce.mcu. es/pdfs/1964_Carta_Venecia.pdf.

${ }^{26}$ En un escrito del Comisario General del Servicio de Defensa del Patrimonio Artístico Nacional en marzo de 1943 al Director General de Bellas Artes del Ministerio de Educación Nacional comunicando la devolución del expediente para la declaración de la iglesia de Santa María la Mayor de Trujillo como Monumento Nacional toda vez que desde la Comisaría se ha emitido informe favorable, se recoge además lo siguiente: "Pero estima esta Comisaría es poco para la importancia monumental de Trujillo esta declaración
Posteriormente, en el año 1947, quince años antes de producirse la declaración de conjunto, el entonces alcalde de Trujillo D. Julián García de Guadiana reitera al Director General de Bellas Artes, señor Marqués de Lozoya, su solicitud de declaración del conjunto como solución a los problemas que la localidad tenía para conservar su rico patrimonio no sólo monumental sino urbano: "Verdaderamente abrumado por la rapidez con que se nos marchan nuestros monumentos, convirtiendo en ruinas una de las ciudades de más valor y sabor de España, me dirijo hoy a $\mathrm{Vd}$. rogándole active en lo posible el expediente para declarar a Trujillo Ciudad Monumental, pues este sería el único medio de salvar a esta desgraciada Ciudad" ${ }^{27}$.

La propuesta llama la atención porque hasta esa fecha pocos conjuntos monumentales se habían declarado en España y en Extremadura sólo se había declarado Guadalupe (1943).

De buena parte de la documentación custodiada en los archivos de la Diputación Provincial de Cáceres y Municipal de Trujillo, se deduce que el interés y la sensibilidad de destacadas personalidades locales fue determinante en este proceso de intentar alcanzar la declaración como conjunto para la localidad ${ }^{28}$. Un proceso muy largo y dilatado

solicitada que debería extenderse al menos a la plaza y al recinto murado que todavía cerca la ciudad alta y produce un contraste violento y típico de la provincia entre sus ennegrecidas piedras y las losas blancas asentadas a su pie. Por consiguiente esta Comisaría al hacer suya la petición citada y en un todo conforme con el informe de la Real Academia de Bellas Artes de San Fernando, la considera solo como un paso previo para alcanzar la total declaración del conjunto". Archivo Central del Ministerio de Educación, Cultura y Deporte (en adelante ACMECUD), Signatura C/87633.

${ }^{27}$ ACMECUD, Sección del Tesoro Artístico, Expediente de obras en la Puerta del Arco del Triunfo de Trujillo (Cáceres), Ministerio de Educación Nacional. Escrito de 20 de Marzo de 1947 del Alcalde de Trujillo al Excmo. Sr. Marqués de Lozoya, Director General de Bellas Artes, con motivo del derrumbamiento de parte de la puerta del Arco del Triunfo.

${ }^{28}$ Hemos de agradecer encarecidamente la atención recibida en estos dos centros y la información facilitada 
pero que constituía un trámite preceptivo para conseguir los fondos necesarios con los que acometer las restauraciones, pues si no estaba formalmente declarado difícilmente se podría intervenir en él ${ }^{29}$.

Todo ese interés por declarar a Trujillo como conjunto se produce además en un contexto en el que su patrimonio arquitectónico presentaba un estado de conservación francamente malo y las distintas fotografías de la época y décadas inmediatas así lo corroboran $^{30}$. De hecho, con relación al resto del territorio extremeño, será una de las pocas localidades cuyo patrimonio sea objeto de atención por parte de la Administración durante el período de "autarquía".

En este sentido ya se había expresado D. José Ramón Mélida Alinari al describir los monumentos trujillanos en el Catálogo Monumental de la provincia de Cáceres ${ }^{31}$, ilustrándolo con fotografías muy significativas del castillo, murallas, casas palacios, iglesias

por los responsables de los mismos.

${ }^{29}$ ACMECUD, Sección del Tesoro Artístico, Expediente de obras en la Puerta del Arco del Triunfo de Trujillo (Cáceres), Ministerio de Educación Nacional. Escrito de 20 de Marzo de 1947. "Excmo. Señor y estimado amigo: con motivo del fuerte y persistente temporal de lluvias la parte antigua de esta ciudad ha sufrido grandes desperfectos pero el de mayor consideración y que a los trujillanos mas nos duele es el derrumbamiento de parte de la puerta conocida con el nombre de 'Arco del Triunfo', de gran valor monumental e histórico. Con este motivo llamé al Sr. Feduchi por teléfono quien a su vez se puso al habla con el Sr. González-Valcárcel quien me escribió comunicándome que nada podía hacerse por la obra, máxime no estando todavía aprobada la declaración de Ciudad Monumental".

${ }^{30}$ Son numerosas las imágenes que se conservan procedentes de distintos fondos: Colección Garrorena de la Diputación Provincial de Badajoz o del Patronato Nacional de Turismo en el Archivo General de la Administración.

31 “Causa penosa impresión ver arruinada la casa solariega de esta familia cuyo nombre enalteció Francisco Pizarro, el Conquistador del Perú. Todo lo que de la casa se conserva es la puerta en arco apuntado". J. R. MÉLIDA ALINARI, Catálogo monumental y artístico de la provincia de Cáceres (1914-1916),Vol. 2, Madrid, 1924, p. 517. y conventos de la localidad. Unas imágenes captadas a muy corta distancia temporal de lo recogido en el documento de 1947 referido con anterioridad y en el que el alcalde de la villa se lamentaba de su mal estado de conservación.

Por otro lado cabe señalar que, hasta la década de los cuarenta, en Trujillo sólo se habían producido dos declaraciones. Por un lado, la del castillo en $1925^{32}$ y, casi dos décadas después, la de la iglesia de Santa María, en 1943. Como señala el profesor Pizarro Gómez refiriéndose a las transformaciones de la ciudad en el siglo XX, "las pérdidas de los valores patrimoniales fueron mínimas", por lo que las obras que el Estado acomete en la plaza mayor de la ciudad serán las más importantes de este período y las más visibles $^{33}$.

Esos dos monumentos citados, el castillo y la iglesia de Santa María respectivamente, serán los únicos en los que la Dirección General de Bellas Artes intervenga hasta el comienzo de las obras en la plaza por la Dirección General de Arquitectura, en el primero de ellos a finales de la década de los cuarenta y a lo largo de toda la década de los cincuenta $^{34}$ y en la iglesia de Santa Ma-

${ }^{32}$ El castillo fue declarado el 7 de Abril de 1925, Gaceta de Madrid, no 108 de 18 de Abril de 1925.

33 "El monumento a Francisco Pizarro levantado en la Plaza Mayor en 1928, merced a la donación de Doña. María Jarriman, viuda del escultor Charles Ramsey, autor de la obra, es, sin duda alguna, uno de los hechos más notables del primer tercio de siglo. Su instalación afectará de manera especial a la definición del paisaje urbano de este espacio y, con él, al del resto de la ciudad, habiéndose convertido en una de las estampas más emblemáticas de la ciudad y asociada universalmente a la imagen de Trujillo y de su Plaza". F. J. PIZARRO GÓMEZ, Trujillo. Paisajes urbanos de Extremadura, Cáceres, 2007, p.117.

34 Mogollón Cano-Cortés, Pizarro Gómez, Fernández-Muñoz y Cases Gómez de Olmedo documentan algunas de estas actuaciones, a las que habría que añadir otras, no referenciadas por ellos y correspondientes a los años 1952, por importe de 45749 pesetas, y 1954, por importe de 84921 pesetas. La primera sobre los aljibes y la segunda alrededor de los torreones. M. P. MOGOLLÓN CORTÉS Op.cit. F. J. 
ría a lo largo de la década de los cincuenta, con hasta seis intervenciones centradas en sus cubiertas y bóvedas principalmente ${ }^{35}$. En todas ellas estará al frente D. José Manuel González Valcárcel siguiendo las pautas del Servicio de Defensa del Patrimonio Artístico Nacional, es decir, ejecutando unas intervenciones centradas en el monumento, que poco a poco van transformándolo a base de proyectos no muy ambiciosos pero constantes y que finalmente modifican el perfil urbano y monumental del conjunto en el que se encuentra.

\section{LA DIRECCIÓN GENERAL DE AR- QUITECTURA Y LAS ACTUACIO- NES EN LA PLAZA MAYOR DE TRU- JILLO}

La transformación completa de Trujillo, o al menos de su principal zona monumental que aquí analizamos, se producirá a comienzos de los sesenta, en el momento en el que a nivel conceptual y jurídico se avanza en torno a la figura de conjunto histórico y las intervenciones sobre los espacios monumentales adquieren, poco a poco, una dimensión urbana con gran protagonismo y sentido escenográfico. En Trujillo, en estos momentos, lo que interesó fue mejorar su "excepcional monumentalidad"36, sirviéndose también para ello de aspectos ligados a la promoción turística de la ciudad, potenciados desde la Administración ${ }^{37}$ y que comenzaban a pre-

PIZARRO GÓMEZ, Op.cit. Y. FERNÁNDEZ MUÑOZ, "Evolución y restauraciones sufridas en el castillo de Trujillo en el siglo XX", Norba Arte, XX-XXI (2000-2001), 2002, pp. 149-162. S. CASES GÓMEZ DE OLMEDO, Op.cit., p.478.

35 M. P. MOGOLLÓN CANO-CORTÉS, La restauración monumental durante la posguerra en Extremadura y la Dirección General de Bellas Artes 19401958, Cáceres, 2011, pp. 251-253.

${ }^{36}$ AGA, Fondo Obras Públicas, Signatura 51/11666, Escrito del arquitecto Jefe de la Sección de Obras de Ciudades Artísticas, Dirección General de Arquitectura, Ministerio de la Vivienda, dirigido al Alcalde de Trujillo con fecha de 19 de noviembre de 1968.

${ }^{37}$ A finales de la década de los sesenta se editaron diversos folletos turísticos de carácter informativo ocupar al consistorio, como se desprende de la lectura de las Actas de las Sesiones de $P_{l e n o}{ }^{38}$. En este sentido también cabe señalar la creación de la Oficina de Turismo que comienza su andadura a finales de 1968 y el relanzamiento de la conocida como Ruta de los Conquistadores ${ }^{39}$, que atravesaba Truji1lo, a comienzos de los setenta.

A las obras realizadas en el castillo, la iglesia de Santa María y el palacio de Orellana Pizarro durante el "primer franquismo" 40 les suceden las actuaciones que sobre palacios y edificios religiosos situados en el entorno de la plaza se van a llevar a cabo en la

sobre el patrimonio trujillano gracias a las ayudas oficiales otorgadas por el Servicio de Promoción Turística del Ministerio de Información y Turismo. Archivo Municipal de Trujillo (en adelante AMT), Libro de Acuerdos de 1965. Acta de la Sesión Ordinaria de Pleno de 3 de agosto, fol. $46 \mathrm{r}$.

${ }^{38}$ Hasta comienzos de la década de los sesenta las principales preocupaciones de la localidad fueron las relativas al alumbrado público, su comunicación con los arrabales y el abastecimiento de aguas. Poco lugar había para aspectos relacionados con la situación en la que se encontraba su patrimonio arquitectónico. Así se deduce de la consulta de actas de las sesiones de pleno del Ayuntamiento de Trujillo custodiadas en el Archivo Municipal de esta localidad. AMT, Libros de Acuerdos desde 1954 a 1964. Actas de las Sesiones Ordinarias de Pleno.

${ }^{39}$ Aunque como señala Pardo Abad la política turística a comienzos de los setenta siguió siendo muy parecida a la de comienzos de los sesenta, en el año 1971 se organizó el territorio español en nueve zonas turísticas y se establecieron a la par ocho grandes rutas por el país. Así, en la zona denominada Lagos de Castilla, se integrarían las provincias de Zamora, Valladolid, Salamanca, Cáceres y Badajoz. Y entre las Rutas junto a la del Camino de Santiago, la del Quijote, la del Arte Hispanomusulmán, la del Románico, la del Gótico, la Ruta de la Fe y la Ruta Colombina, habría que señalar también la Ruta de los Conquistadores. No obstante, las primeras referencias de esta ruta se remontan a los años 1952 y 1953, cuando se está redactando el Plan Nacional de Turismo (nuestro agradecimiento al doctor D. Nicolás Torres Camacho por facilitarnos esta información). C. J. PARDO ABAD, Territorio y recursos turísticos. Análisis geográfico del turismo en España, Madrid, 2013, pp.166-167.

40 M. P. MOGOLLÓN CANO-CORTÉS, La restauración monumental durante la posguerra..., pp. 246255. 


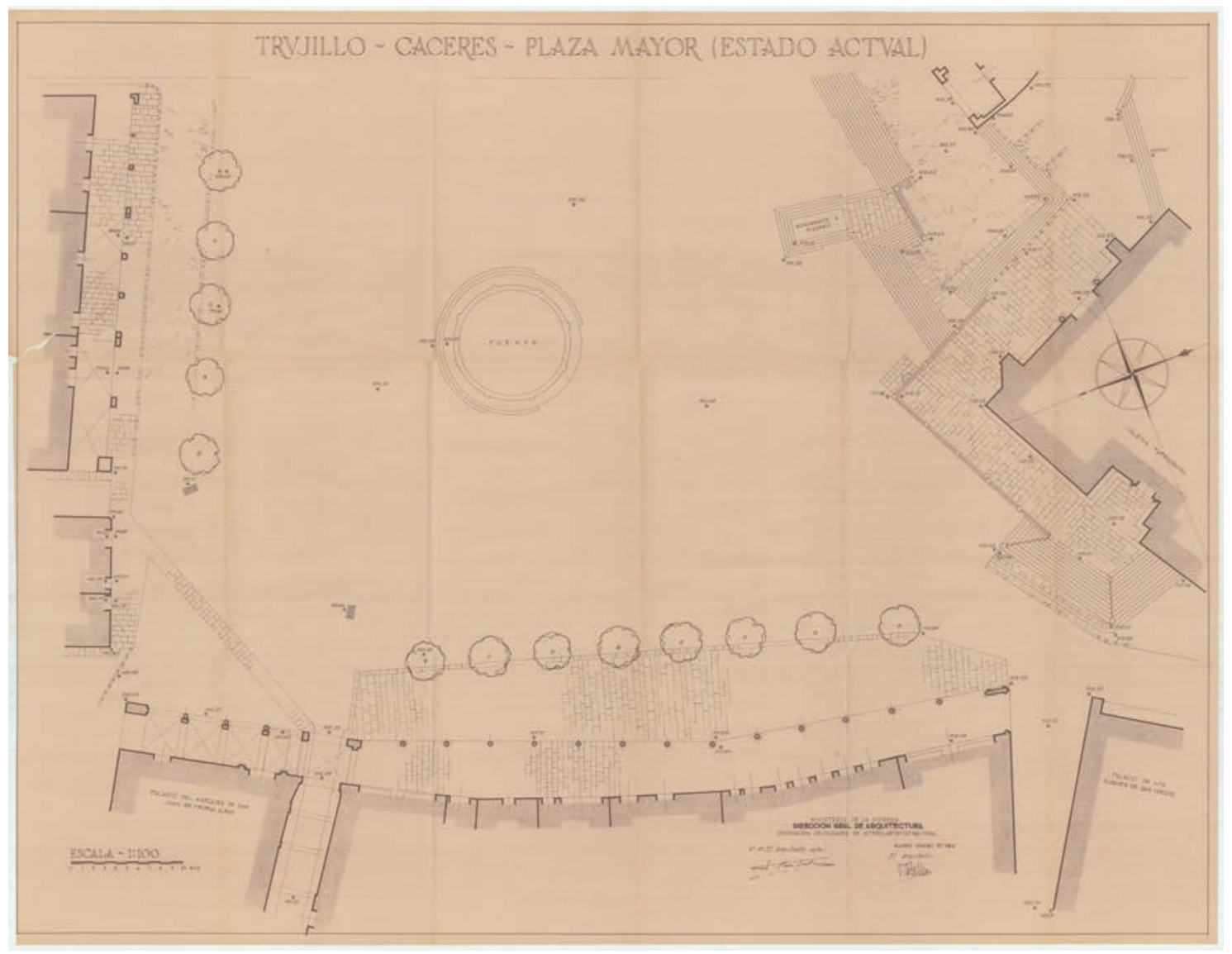

- Fig. 1. Zona nororiental de la plaza mayor de Trujillo a finales de la década de los cincuenta, con anterioridad a las actuaciones de la DGA. Foto: Archivo General de la Administración, Signatura 51/11668, Proyecto de ordenación de la Plaza Mayor de Trujillo (Cáceres), Ministerio de la Vivienda, Dirección General de Arquitectura.

década de los sesenta desde la Dirección General de Bellas Artes ${ }^{41}$, así como las que afectaron a la plaza que son objeto de análisis en este estudio desde la Dirección General de Arquitectura.

El proyecto que la Dirección General de Arquitectura diseña para la plaza de Trujillo se realizó tres años antes de su recono-

${ }^{41}$ S. CASES GÓMEZ DE OLMEDO, Op.cit., pp. 478-481. En este trabajo se recogen las actuaciones ya citadas del castillo $(1947,1951,1958,1963,1970,1971$, 1973, 1974, 1978), la iglesia de Santa María (1950, 1951, $1953,1955,1956,1957,1963,1965,1971)$ y las del palacio de Orellana $(1959,1961,1963,1975)$ además de las que se desarrollen en los años sesenta y setenta en las casas de los Calderón y Pizarro, los conventos de la Merced, San Francisco el Real y San Pedro, las iglesias de San Francisco y San Martín, el monasterio de las Jerónimas, o los palacios de Chaves, el de la Conquista, Lorenzana y San Carlos. cimiento como conjunto monumental, aprobándose en diciembre de 1959. En él se recogían las directrices estéticas responsables del cambio de imagen de un espacio que mantiene a día de hoy esa misma configuración. Fueron unas obras que se dilataron mucho en el tiempo, casi diez años, pero que se concibieron desde el primer momento de manera global aunque se desarrollaran, sin embargo, en fases bien distintas (Fig. 1) ${ }^{42}$.

\footnotetext{
42 “Organización armónica de las calles que constituyen el nivel alto de la Plaza, respetando, con modificaciones de mejora, sus rasantes naturales, y modelando por medio de rampas y escaleras que amplían o mejoran las actuales, el sentido ascensional de todo el caserío hacia el ángulo N.O. por donde sale la calle -en fuerte rampa- que nos conduce a la vieja Ciudad Alta". AGA, Fondo Obras Públicas, Signatura 51/11666, Memoria del Proyecto de ordenación parcial de la Plaza Mayor, ángulo S.O y pasadizo hacia el
} 


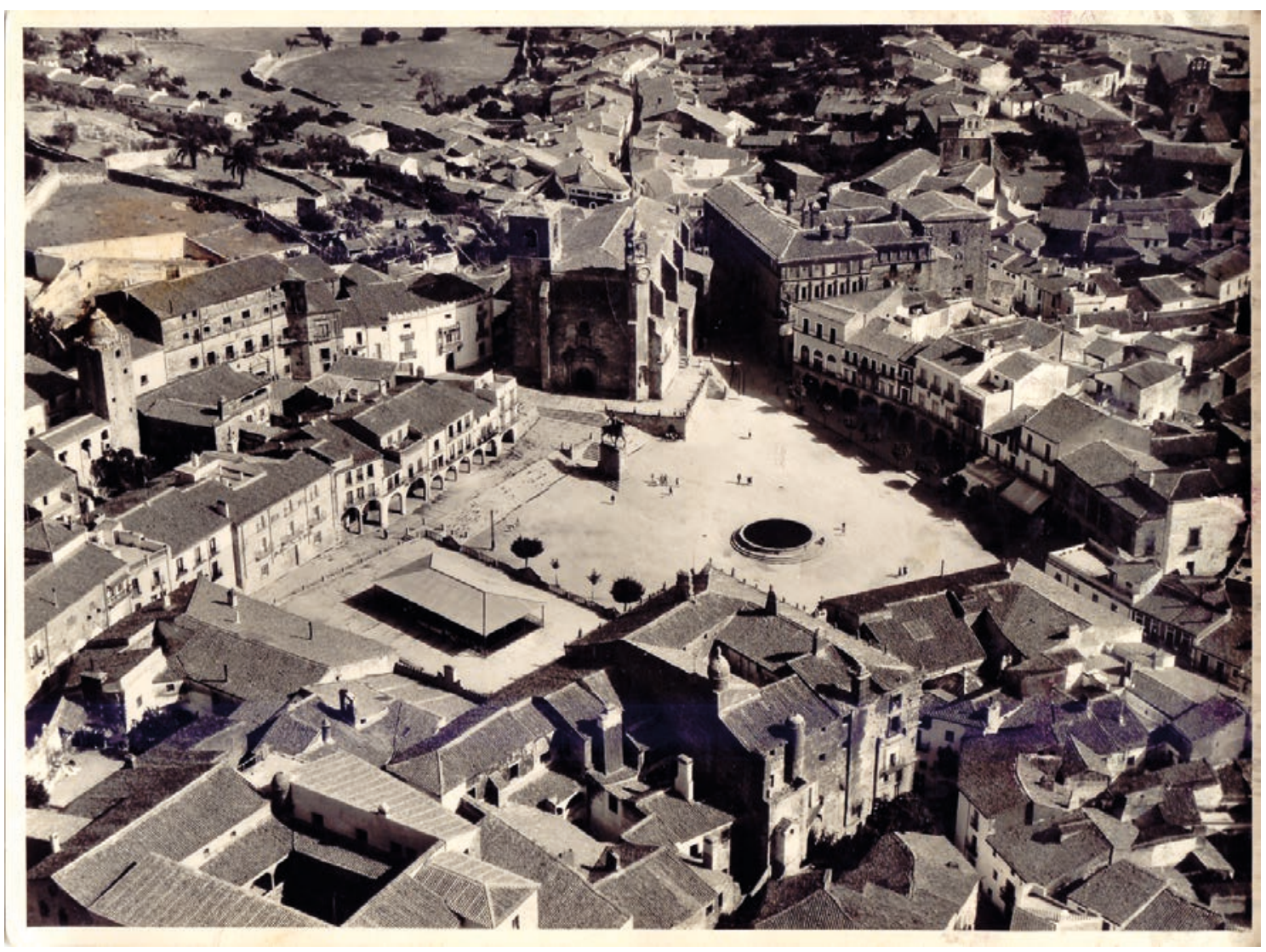

- Fig. 2. Vista aérea de la plaza a finales de la década de los cincuenta, antes de las intervenciones. Foto: Archivo Municipal de Trujillo.

Las razones que motivaron el proyecto coinciden con lo que el Alcalde de la localidad, a finales de 1960, recoge en un escrito dirigido al Director General de Arquitectura, señalando que a la plaza "le falta simetría y le sobran aditamentos que ocultan su grandiosidad" 43 .

En su lado suroccidental, edificios tan significativos como el palacio del Marqués de la Conquista, las Casas Consistoriales Viejas y el palacio de Hernando Pizarro permanecían casi escondidos debido a la instalación del mercado municipal en el solar situado justo delante de ellos, que ciertamente desvirtuaba bastante la imagen de la plaza y de los edificios históricos colindantes. Ese

palacio de Orellana.

${ }^{43}$ Ibídem, Escrito de 13 de diciembre de 1960 del Excmo. Sr. Alcalde de Trujillo, D. Manuel Pablos Mateos al Director General de Arquitectura. era pues, según consta en el proyecto, el principal obstáculo (Figs. 2 y 3).

En el lado opuesto, el nororiental, dominado por la iglesia de San Martín y el palacio convento de San Carlos, los problemas que se presentaban eran otros, fundamentalmen-

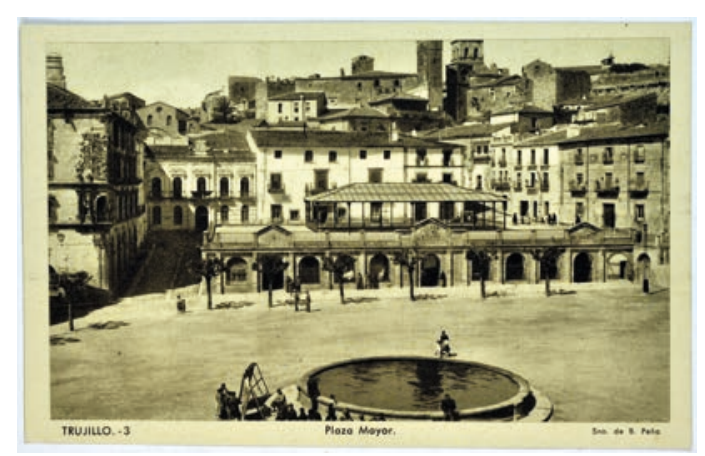

- Fig. 3. Aspecto del mercado antes de su demolición y del ángulo suroccidental de la plaza con la fachada que será demolida en 1957. Foto: Diputación provincial de Cáceres. 


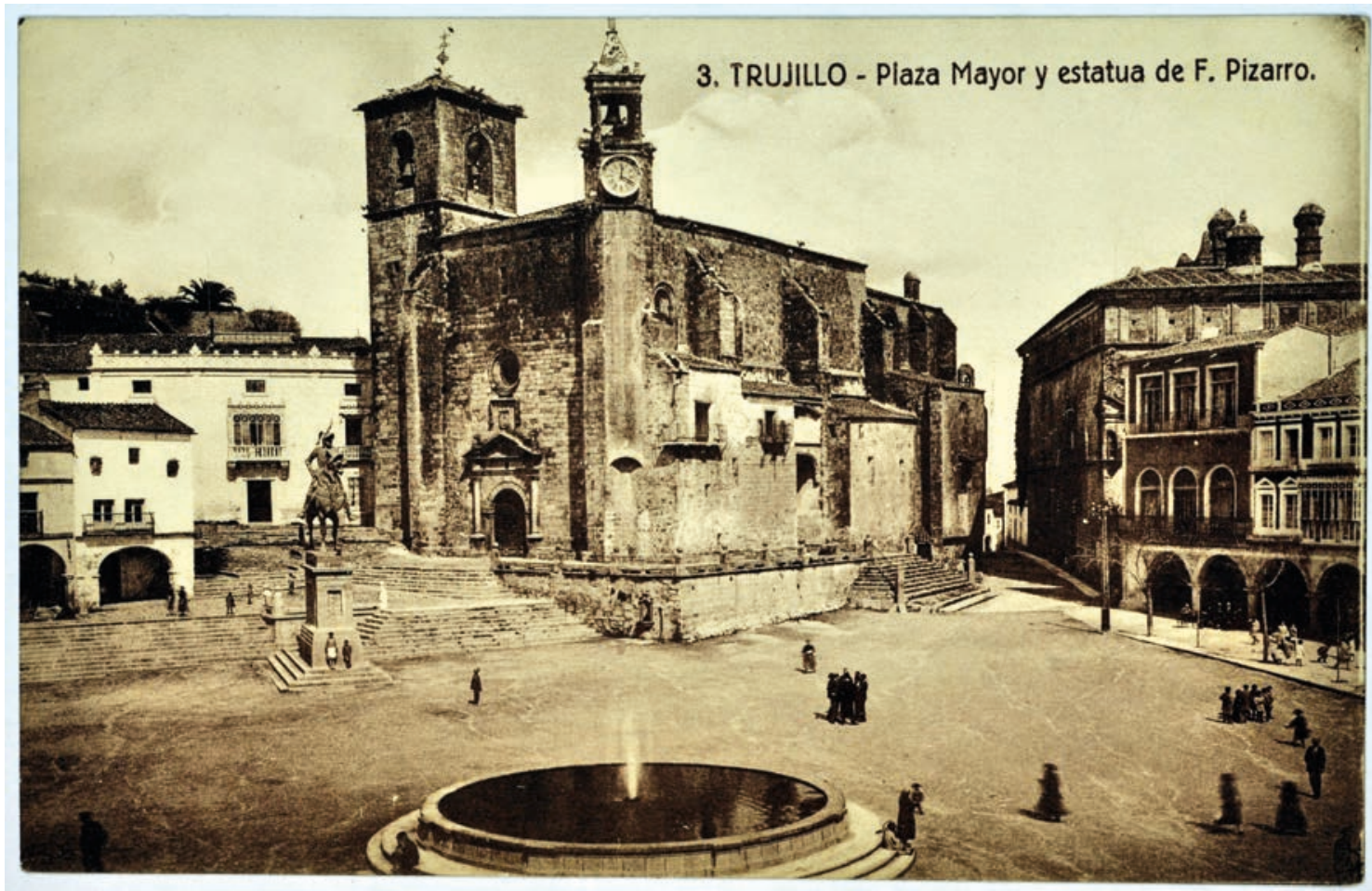

- Fig. 4. Ángulo nororiental de la plaza con la iglesia de San Martín en primer término y al fondo el palacio de San Carlos con la galería de ventanas aún cegadas anterior a 1960. Foto: Diputación provincial de Cáceres.

te en el pavimento, muy desnivelado y con acusadas pendientes de terreno que había que salvar en algunas zonas (Fig. 4). El estado de conservación de los pavimentos y los distintos elementos de fábrica también dejaba mucho que desear, especialmente en los soportales próximos a San Carlos.

En base a lo anterior, desde el Servicio de Ciudades Histórico Artísticas (dependiente de la Dirección General de Arquitectura) se concibió un proyecto para despejar este gran espacio urbano y mejorar las condiciones de visibilidad del lado suroccidental. Del mismo modo se facilitaría una mejor conexión de la parte baja de la ciudad con la alta, donde se alzaban la iglesia de Santa María y el castillo, hitos monumentales de la localidad. Por ello se contempló como absolutamente necesaria la demolición del mercado, el posterior enrasado de toda la solera de la plaza -complejo al tener que sortear importantes desniveles de terreno-, la consolidación de los soportales y el remozado de todas las fachadas de los edificios que la rodeaban. En estos últimos trabajos intervendría además la Dirección General de Bellas Artes.

La remodelación de la plaza se concebía de una forma integral aunque se acometería en varios proyectos. El primero sería el de Ordenación parcial de la Plaza Mayor, ángulo S.O y pasadizo hacia el palacio de Orellana de 1959 donde se contempló desarrollar tres actuaciones $^{44}$ :

1. La "organización armónica de las calles...que nos conduce a la ciudad alta".

2. La "liberación de perspectivas que afectan al soportal del Palacio de Hernando Pizarro".

3. El acceso al pasadizo de comunicación con el palacio de Orellana desde el edificio de las Viejas Casas Consistoriales

${ }^{44}$ AGA, Fondo Obras Públicas, Signatura 51/11666, Memoria del Proyecto de ordenación parcial de la Plaza Mayor, ángulo S.O. y pasadizo hacia el palacio de Orellana. 


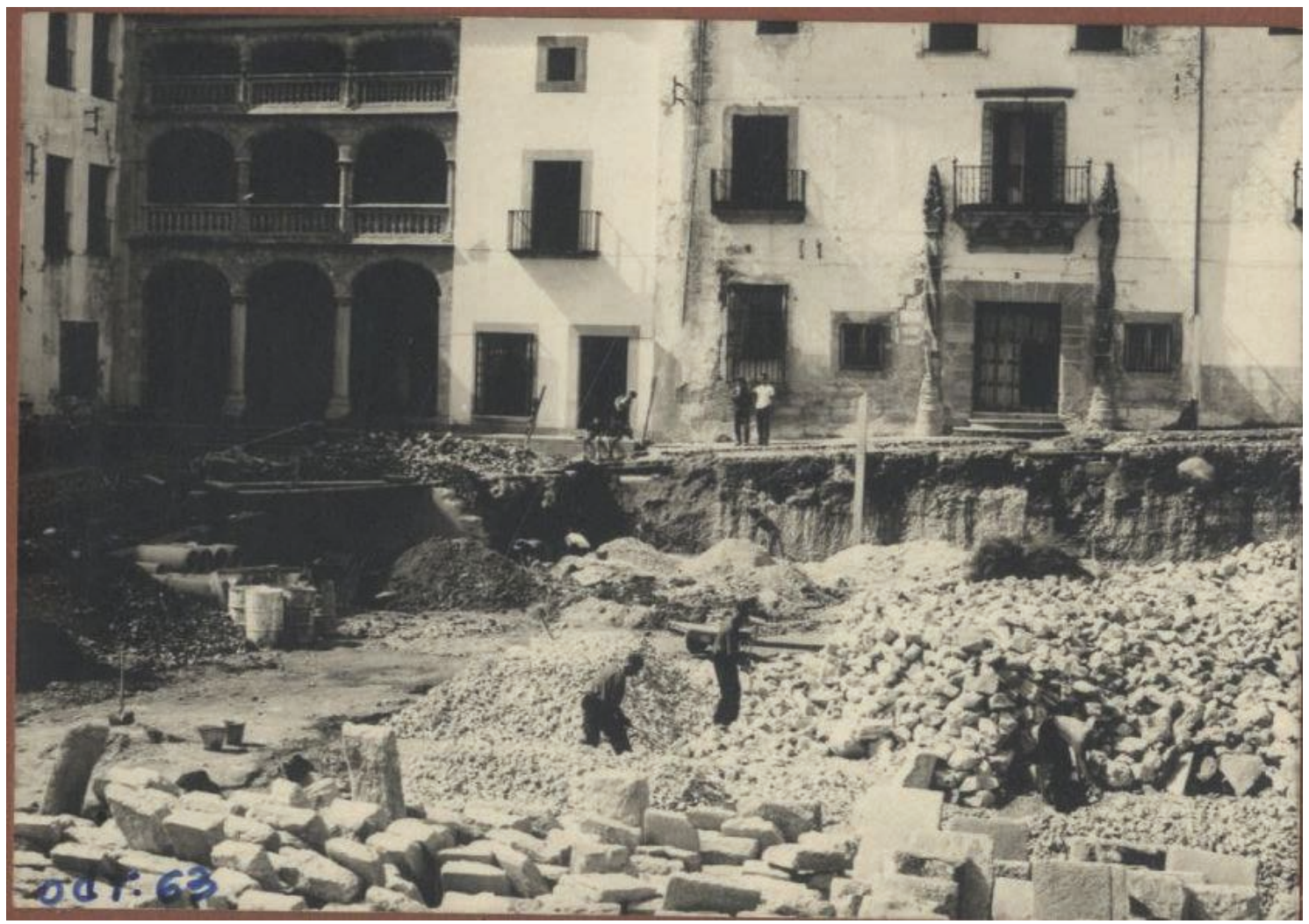

- Fig. 5. Aspecto del lado suroccidental durante las obras de demolición del mercado en 1963. Foto: Archivo General de la Administración, Signatura 51/11667, Proyecto de ordenación de la Plaza Mayor de Trujillo (Cáceres), Ministerio de la Vivienda, Dirección General de Arquitectura.

con afectación de una de las fachadas del palacio del Marqués de la Conquista.

No obstante este ángulo suroccidental de la plaza ya había comenzado a transformarse dos años atrás, afectando dicho cambio a la fachada de las denominadas Casas Consistoriales Viejas de las que se eliminó la fachada preexistente para proceder a su sustitución por otra, procedente del patio de un inmueble cercano del siglo XVI (Fig. 5) ${ }^{45}$. El cambio, muy notable, alteró radicalmente el aspecto exterior del edificio y ese ángulo de la plaza, ajustándose desde el punto de vista estético a los planteamientos de las Direccio-

45 "Recientemente, el Ayuntamiento de Trujillo ha trasladado una antigua fachada de patio del siglo XVI al ángulo S.O. de la plaza, dando bella fachada al rincón de las Casas Consistoriales Viejas y pintoresco pasadizo que lleva a la Plazuela de Orellana donde se alza otro de los más nobles palacios de Trujillo". AGA, Fondo Obras Públicas, Signatura 51/11666. nes Generales de Arquitectura y de Bellas Artes, que actuarían de un modo similar en otras localidades extremeñas ${ }^{46}$ y españolas ${ }^{47}$. Se consiguió así un rincón que se adecenta-

${ }^{46}$ En el trabajo de Tena Fernández y en proceso de elaboración al mismo tiempo que se realizan las obras de remodelación de la plaza mayor de Trujillo se indica que “...las obras de restauración de la fachada principal de este edificio [Ayuntamiento Viejo] comenzadas en 1957, culminaron en la bellísima ornamentación del vestíbulo porticado y en las dos galerías claustradas abiertas en la parte superior. Sus respectivas balaustradas son de la misma traza gótica. Las columnas son fasciculadas y a excepción de diversos fustes, basas y capiteles de algunas columnas que son obra de obreros trujillanos, las demás piezas que son de grande valor artístico, también lo tienen histórico, pues proceden del patio central de la casa del número 10, en el portal alto de la Plaza y la cual perteneció a una rama del linaje de los Cervantes Gaete...". J. TENA FERNÁNDEZ, Trujillo Histórico y Monumental, Trujillo, 1966, p.330.

47 E. MORAIS VALLEJO "Traslado de edificios históricos. El caso de León durante la etapa franquista", De Arte, no 1, 2002, pp. 113-137. 
ría con la mejora del acceso a esta zona desde el palacio del Marqués de la Conquista y que facilitaría la comunicación con otros inmuebles y espacios muy destacados artísticamente, como el palacio de Orellana y su entorno urbano, desconocidos e infravalorados por no estar situados en la plaza sino en sus proximidades (Fig. 6).

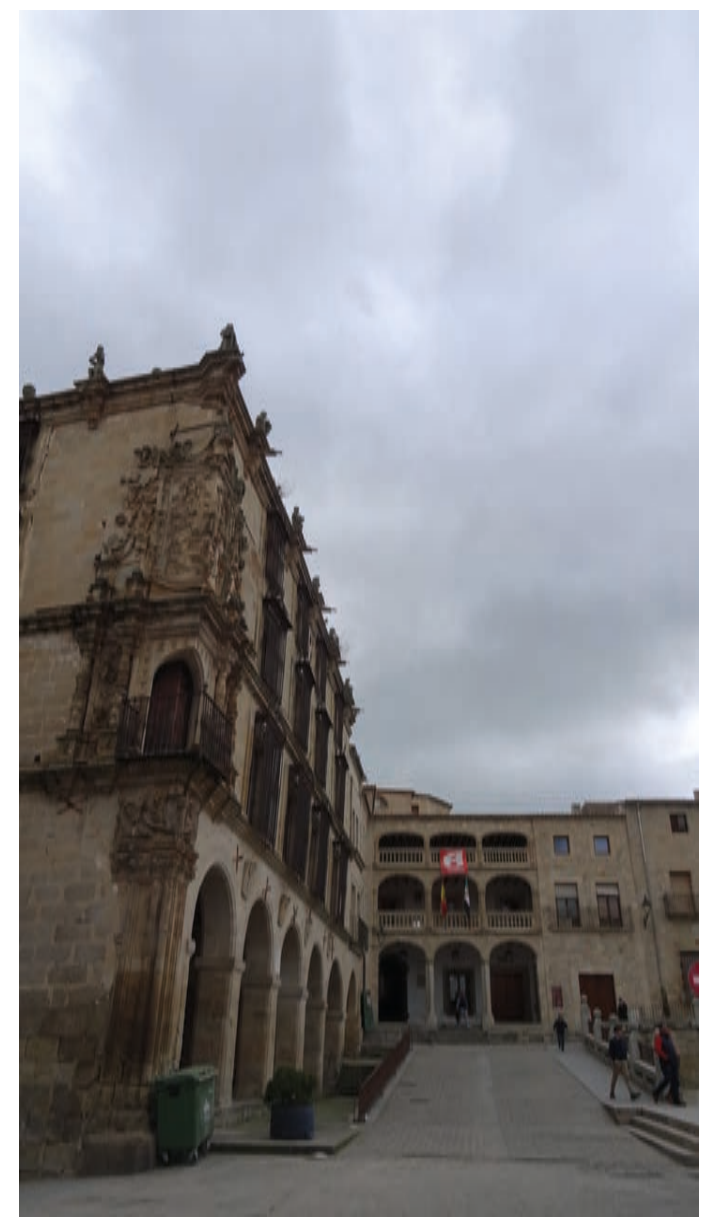

- Fig. 6. Rampa de acceso a las Casas Consistoriales Viejas en la actualidad. Foto de la autora.

El proyecto no pudo ejecutarse en su totalidad "dadas las reducidas posibilidades económicas...y la dificultad ya apuntada de supresión actual del mercado"48. Había no solo que demoler el actual mercado sino trasladar esta función a otra zona de la lo-

48 AGA, Fondo Obras Públicas, Signatura 51/11666, Memoria del Proyecto de ordenación parcial de la Plaza Mayor, ángulo S.O. y pasadizo hacia el palacio de Orellana. calidad y adecuar o construir un inmueble apropiado para ello. El escollo más grave que había que sortear era el de conseguir la financiación necesaria para la construcción de un nuevo mercado, pese a lo cual el plan de ordenamiento recogido en el proyecto no se modificaría y éste se ejecutaría parcialmente. Se dejaron pendientes las actuaciones del lado nororiental y la "liberación de perspectivas" del palacio de Hernando Pizarro, ejecutándose el acceso a las Casas Consistoriales, con la rampa que vemos en la actualidad, y el pasadizo de comunicación entre el palacio de Orellana y las Casas Consistoriales, remodelando uno de los arcos de su fachada.

La demolición del mercado se llevaría a efecto finalmente en $1963^{49}$, con la ejecución de un nuevo proyecto que mantendría los mismos objetivos marcados en 1959: dotar de una perspectiva monumental al lado suroccidental de la plaza, antesala del acceso a la Villa Adentro medieval. Al fin comenzaba el derribo del mercado de abastos que permitiría la liberación de fachadas adyacentes y ordenación del espacio que se generaría tras el derribo de tan "lamentable edificación desencajada en espíritu y planta" (Fig. 3) 30. $^{50}$. Una tarea compleja debido a los fuertes desniveles de terreno que habrían de sortearse con un gran muro de contención (en mampostería careada concertada) en cuyo arranque se abrirían locales comerciales con acceso desde la parte baja de la plaza. Frente a estos locales, una plataforma peatonal daría lugar a una nueva plaza en la que a petición del Ayuntamiento se construiría un pequeño estanque. El material a utilizar en todas las actuaciones sería la piedra de la zona.

Un capítulo importante en este segundo proyecto lo constituyó la pavimentación de la plaza y la supresión de la fuente o pilón central que habría de generar una encendida polémica entre el consistorio y el Ministerio

${ }^{49} \mathrm{Ibídem}$, Signatura 51/11668, Proyecto de ordenación de la Plaza Mayor de Trujillo (Cáceres), Ministerio de la Vivienda, Dirección General de Arquitectura.

${ }^{50}$ Ibídem. 
de la Vivienda, pues en el proyecto se concibió desde un principio enarenar la plaza sobre una solera de hormigón en masa y suprimir la fuente para evitar filtraciones. Tres grandes espacios triangulares separados por unos pasillos de losas graníticas confluirían a la altura del monumento a Pizarro que se convertía así en el eje central del gran frente o fachada norte de la plaza. Las aceras junto a los soportales tendrían también un pavimento de losas de granito sin bordillos y las calles de acceso a la ciudad alta lo tendrían con granito y morrillo. Al variar levemente la rasante de la plaza en su zona Este se procedería también a recalzar las bases de las arquerías. Por último, los trabajos se extenderían también por el entorno inmediato de la iglesia de San Martín, concretamente a su balconada y escalinata.

Con estas actuaciones sobre los lados menores de la plaza, cobraría entonces un gran protagonismo uno de los lados mayores, su lado norte, el frente con mayor visibilidad de toda la plaza y el que le otorga su mayor monumentalidad. Serían por tanto tres grandes fachadas las que se presentarían al turista: el ángulo suroccidental con especial protagonismo otorgado al nuevo frente del Ayuntamiento, engrandecido por su proximidad al palacio del Marqués de la Conquista y la restauración en estilo de su nueva fachada; el frente norte, dominado por edificios "menores" sobre soportales y de gran longitud, cuyo desnivel sobre la rasante de la plaza se sortearía con una ancha escalinata; y el ángulo nororiental que arrancaría a partir de la escultura de Francisco Pizarro próxima a edificios tan emblemáticos como la iglesia de San Martín, el convento de Jerónimas (o palacio de San Carlos) y una nueva línea de soportales con arquitectura menor pero de importante peso visual para alcanzar la deseada "armonización" y "ambientación" del espacio placero.

Se quería "ennoblecer" la plaza (así se recoge en el proyecto) desde distintas perspectivas, aunque no se correspondieran estas con la secuencia histórica original de la misma, justificando esta actuación en un cri- terio de armonía muy ambiguo y característico del Servicio de Ordenación de Ciudades de Interés Artístico. El que las fachadas principales y secundarias de otros edificios de la plaza se vieran restauradas en esta misma década, algunas bajo la Dirección General de Arquitectura y la mayoría bajo la Dirección General de Bellas Artes, pone de manifiesto la gran importancia concedida a este espacio, la subsidiariedad del resto de inmuebles para con el mismo y el interés por definir un espacio nuevo bajo criterios de intervención no siempre garantes de la autenticidad histórica.

En una carta dirigida a finales de 1960 por la Priora General de la Orden Jerónima establecida en el palacio de San Carlos, al Director General de Arquitectura, D. Miguel García Lomas, se constata todo lo anteriormente referido; pues la superiora, consciente de que una modificación del espacio de la plaza sin las restauraciones de las principales fachadas que miran a la misma desmerecería y mucho a un proyecto tan ambicioso, señala lo siguiente:

"...me he encontrado con un edificio tan noble, en la maravillosa plaza de Trujillo (un Toledo extremeño) que sería un pecado artístico y patriótico no tratarlo como a tal. Y como Valcárcel, que es el arquitecto, engolosinado con lo de Yuste, quiere también hacer una obra digna, me está subiendo el presupuesto por encima de mis posibilidades. Pues resulta que hemos descubierto una galería preciosa de labradísimos capiteles, una portada almohadillada, toda de piedra que da al exterior...hay que abrir los tres amplísimos arcos de la loggia italiana con acento extremeño...

Todo ello va, no en favor de la Comunidad, que pierde terreno y edificio, sino en bien de la plaza que va a hermosearse con un palacio que tal vez sea el mejor de Extremadura. Por no cerrarlo al turismo, he pedido a la Santa Sede licencia para que, no obstante la clausura papal, pueda enseñarse el interior (patio y escalera) a horas determinadas... 
Me han dicho en Trujillo que Ud. siente gran admiración por la ciudad de los Conquistadores; que intenta arreglar la plaza y que cuenta para ello con un presupuesto especial. ¿Será atrevimiento pedirle una participación para San Carlos? ¿Precisamente para el arreglo y embellecimiento de la fachada que da a la plaza? Me dice el contratista que habría que gastar en ella unas 300000 y no quiero ni pensarlo...De todos modos, Valcárcel puede enterarle, mejor que nadie, de la verdad del caso y de lo que agradecerá el auxilio que puedan darme. Confío en su interés por Trujillo, una de las ciudades españolas que es preciso revalorizar...y en la promesa evangélica que dice: 'Pedid y recibiréis, llamad y se os abrirá'...con esta esperanza llama a sus puertas y queda a sus órdenes...Sor Cristina de la Cruz Arteaga" ${ }^{51}$.

San Carlos pues sería restaurado, concediendo especial protagonismo a su fachada, a la que se le liberarían las arquerías cegadas del piso superior desde un criterio de intervención más respetuoso con la fábrica histórica y cercano a posiciones del restauro moderno o filológico que a como se hiciera unos años atrás con la fachada de las casas consistoriales (Fig. 7).

Esta subordinación de las fachadas que miran a la plaza o forman parte del entorno de la misma, afectó también a otros edificios sin valor histórico-artístico reconocido. Se trató de viviendas particulares y locales comerciales en cuyos expedientes de obra se constataron recomendaciones sobre el uso de la piedra de cantería para los zócalos de las fachadas y recercados de huecos; sugerencias para la supresión de materiales como el ladrillo visto, con el "...fin de evitar una falta de ambientación con el fondo" [refiriéndose a la plaza y la villa adentro] y en

\footnotetext{
${ }^{51}$ Ibídem, Carta de la Priora General de las Jerónimas - Sor Cristina de la Cruz de Arteaga-, desde la Casa Madre en el Monasterio de Santa Paula de Sevilla, al Ilmo. Sr. Don Miguel García Lomas, Director General de Arquitectura, 8 de diciembre de 1960. Manuscrito, al final del texto la siguiente nota: Para que Pons Sorolla vea lo que se puede hacer con gran interés...
}

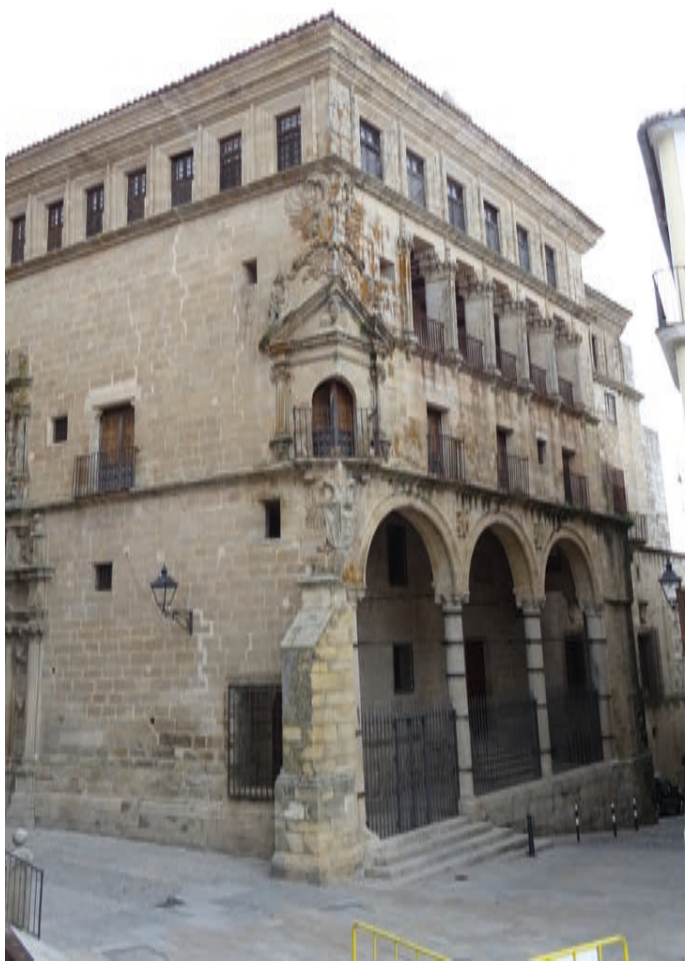

- Fig. 7. Palacio de San Carlos con la galería superior descubierta en la actualidad. Foto de la autora.

definitiva no desentonar con la imagen que se pensaba proyectar de la ciudad ${ }^{52}$.

La ejecución de este segundo proyecto, que concluyó aproximadamente a finales de 1966 con la pavimentación ya señalada, no dio lugar a la finalización de las obras, que se dilataron hasta 1969. En octubre de 1968 volvieron a iniciarse los trabajos en la pavimentación de la plaza aunque los motivos por los que así fue no están muy claros a tenor de la documentación cotejada. Desde el Ayuntamiento se atribuyeron a "las pobres mezclas de pavimentos...y mala calidad

\footnotetext{
${ }^{52}$ La información aportada en esta cita corresponde a un expediente facilitado amablemente en el Archivo General de la Administración a requerimiento del investigador y que aún no está catalogado y preparado para su consulta en sala, de ahí que no se tenga la referencia archivística exacta.
} 
del granito empleado" las causas de esta "re-pavimentación" ${ }^{53}$. Por parte de la Dirección General de Arquitectura estos nuevos trabajos constituyeron una mejora sobre la pavimentación existente, que no era de mala calidad pero que sin embargo presentaba deterioros producidos por la instalación de estructuras de madera para la celebración de unas capeas populares. Fueron varios los escritos que cruzaron el Ayuntamiento y la Dirección General de Arquitectura en donde además se solicitó a esta última la instalación de algún elemento en el centro de la plaza "que rompiera la excesiva aridez de una superficie tan extensa" ${ }^{54}$. Propuestas no faltaron, desde el Rollo de Término situado en la actualidad a la salida de la población por la calle Campillo (N-521) en dirección a Guadalupe (EX-208), pasando por la farola que existió a principios de siglo, hasta la fuente o pilón que finalmente hoy se puede ver.

Llaman la atención las diversas sugerencias del consistorio así como la aceptación por parte de la Dirección General de Arquitectura de parte de las mismas, sobre todo la del pilón central, por lo que supone estéticamente (aunque tuviese su correspondencia con una de las secuencias históricas de este espacio), así como la ruptura del criterio estético de la Dirección. Eso pone de manifiesto la facilidad con la que podían cambiarse los elementos de este escenario y corrobora esta condición de telones escenográficos creados al amparo de una nueva concepción de lo auténtico y de reinterpretación histórica.

Tampoco hay que olvidar el importante papel que el turismo había comenzado a desempeñar en la práctica de la restauración monumental. De hecho, a comienzos de la década de los setenta se produce el relanzamiento de la Ruta de los Conquistadores, cuyo origen ha de remontarse a la década de

${ }^{53}$ AGA, Fondo Obras Públicas, Signatura 51/11666, Escrito dirigido por el Excmo. Alcalde de Trujillo al Sr. Arquitecto Jefe de la Sección de Obras de ciudades Artísticas con fecha 31 de octubre de 1968.

\footnotetext{
${ }^{54}$ Ibídem.
}

los cincuenta. En esta ruta Trujillo se convertía en una parada obligada proyectándose a nivel nacional como un destino de fuerte atractivo histórico- artístico ${ }^{55}$. No en vano presentaba a los turistas un rico patrimonio arquitectónico recién remodelado que será utilizado como imagen publicitaria por el Instituto de Estudios Turísticos para promocionar la ciudad a mediados de los setenta a través de sus muchos carteles turísticos (Figs. 8, 9, 10, 11 y 12).

\section{CONCLUSIÓN}

La valoración e interés que los conjuntos histórico-artísticos españoles despertaron en las décadas de los sesenta y setenta en la administración franquista fue muy destacada y coincidió a nivel europeo con la importancia que estos adquirieron sobre todo a partir de la redacción de la Carta de Venecia en 1964, en la que se amplió la definición de monumento.

En el contexto nacional y a nivel teórico, el término evolucionó a partir del concepto de monumento establecido por la legislación de 1933, vigente aún en la década de los sesenta -arco temporal de las intervenciones desarrolladas en la plaza mayor de Trujilloaunque con ampliaciones y modificaciones. Normativamente, por su coincidencia en el tiempo con las obras aquí analizadas, se destacan las Instrucciones para la defensa de los conjuntos histórico artísticos de 1964, por cuanto pusieron de relieve ese interés por los conjuntos proporcionando una definición de los mismos e intentando regular las intervenciones sobre ellos aunque con resultados desiguales.

En el ámbito de la práctica restauradora el conjunto histórico-artístico fue tratado

${ }^{55}$ La tesis de D. Nicolás Torres Camacho, defendida en la Universidad de Castilla la Mancha en 2017 y dirigida por las doctoras García Cuetos y Cañizares Ruiz bajo el título Turismo y patrimonio. Gestión turística y recursos patrimoniales en el franquismo: las denominaciones geoturísticas, aborda las vinculaciones entre la política turística y de restauración monumental en el período franquista. 


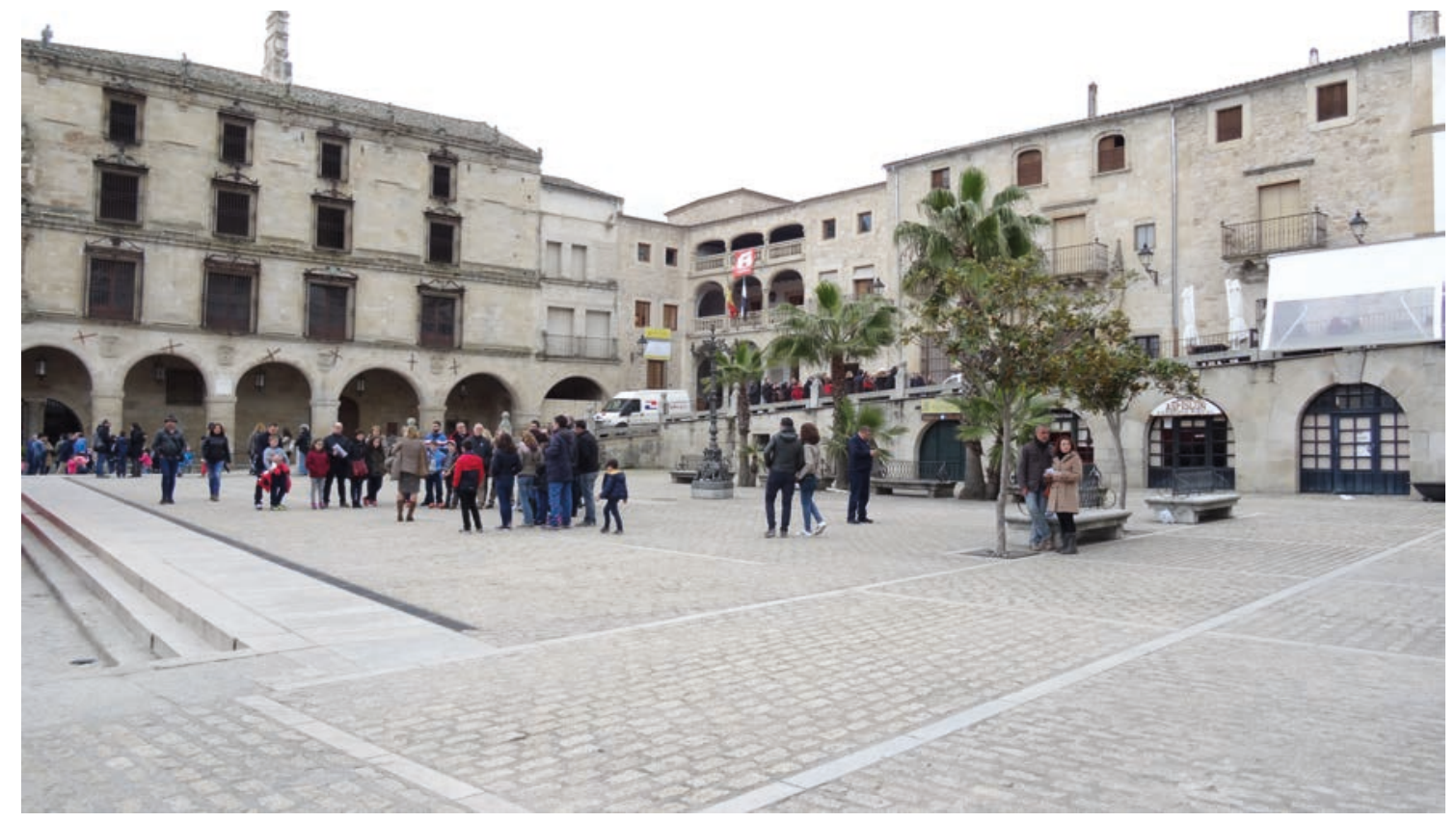

- Fig. 8. Nueva plaza generada tras la demolición del mercado y locales comerciales en el muro de contención, en la actualidad. Foto de la autora.

como un gran monumento o conjunto de estos, consideración esta última fruto de la evolución normativa referida, la cual va otorgando una importancia cada vez mayor a las arquitecturas y espacios circundantes en torno a los edificios singulares y que se observa en el caso de las obras acometidas en Trujillo a lo largo de la década de los sesenta, tanto por parte de la Dirección General de Bellas Artes como por la Dirección General de Arquitectura, la primera preocupada principalmente por los monumentos aislados y la segunda centrada en los conjuntos histórico-artísticos desde su Sección y posterior Servicio de Ordenación de Ciudades Histórico-Artísticas.

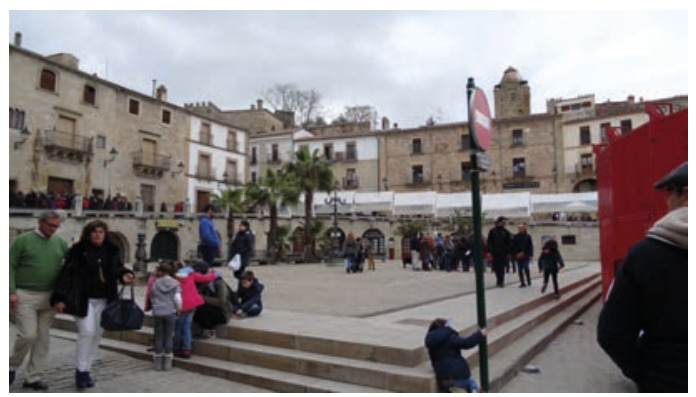

- Fig.9. Otro ángulo del nuevo espacio abierto creado tras la demolición del mercado en la actualidad. Foto de la autora.
Los proyectos abordados en la Plaza Mayor de Trujillo desde la Dirección General de Arquitectura y prácticamente todos los que esta ejecuta en Extremadura desde su creación, respondieron en buena medida al deseo de generar un gran marco escenográfico para la promoción turística de las zonas declaradas -interés turístico que comienza a despegar con fuerza-; sin perder la conexión con las connotaciones ideológicas y simbólicas que subyacen detrás de cualquier proyecto de restauración, y que abundaron sobre todo durante el "primer franquismo". Reconocer como conjuntos históricos-artísticos ciudades y pueblos con un pasado ilustre y con personajes históricos

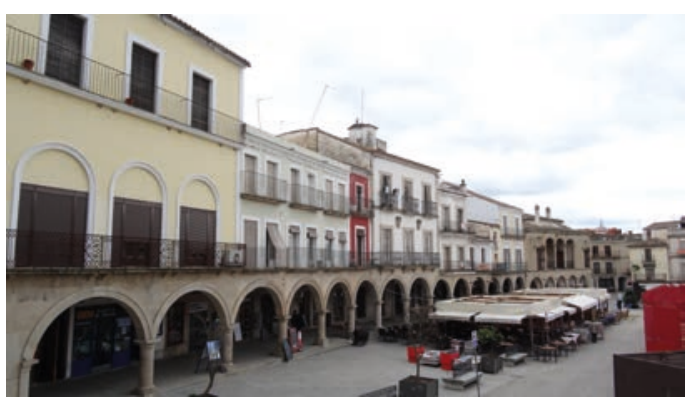

- Fig. 10. Soportales de la plaza en su lado nororiental en la actualidad. Foto de la autora. 


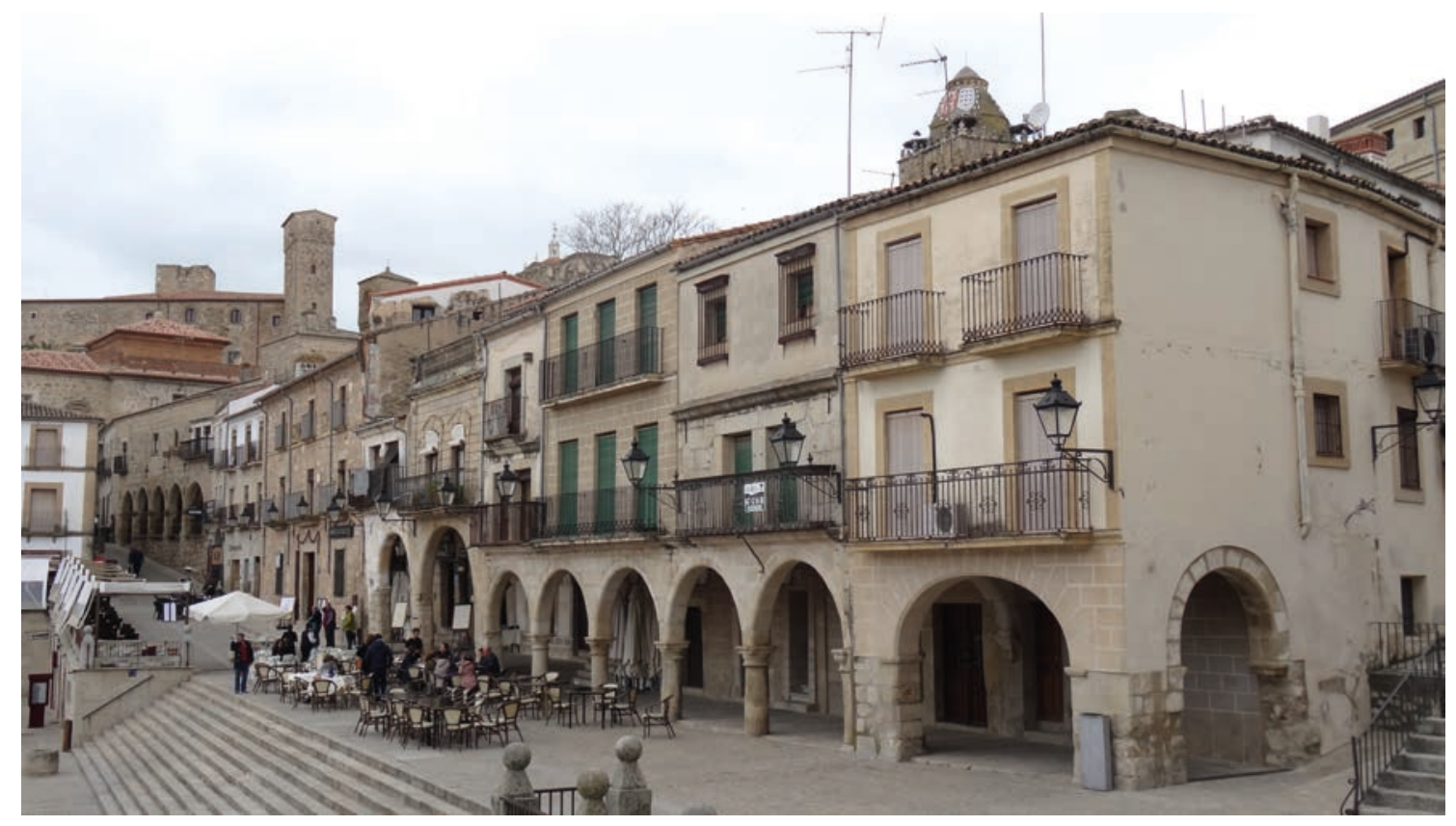

- Fig. 11. Soportales de la plaza en el frente norte que comunica con la Villa Adentro en la actualidad. Foto de la autora.

relevantes respondía a los mismos criterios por los cuales Franco decidió restaurar en el período de "autarquía" monumentos muy significativos de la historia de España para la redefinición de la identidad nacional y la legitimación de su régimen político.

Liberación de perspectivas, armonización, ennoblecimiento...fueron algunos de los términos ambiguos que permitieron a los arquitectos de la Dirección General de Arquitectura, desde el Servicio de Ordenación de Ciudades Históricas, actuar sobre las fábricas, y en menor medida las tramas urbanas. Fueron en realidad los mismos que aparecieron también en los proyectos de intervención de la Dirección General de Bellas Artes desarrollados por arquitectos que también trabajaron para la Dirección General de Arquitectura. Así ocurrió con el arquitecto de la $5^{\text {a }}$ zona a la que perteneció Trujillo, D. José Manuel González Valcárcel y con el propio director del Servicio de Ordenación de Ciudades Históricas, D. Francisco Pons Sorolla, profesionales implicados en las restauraciones de Trujillo a lo largo de la década de los sesenta.
La Dirección General de Bellas Artes contribuyó a la recreación de la imagen patrimonial de Trujillo subordinando los distintos proyectos de cada monumento en los que intervino al gran proyecto de ordena-

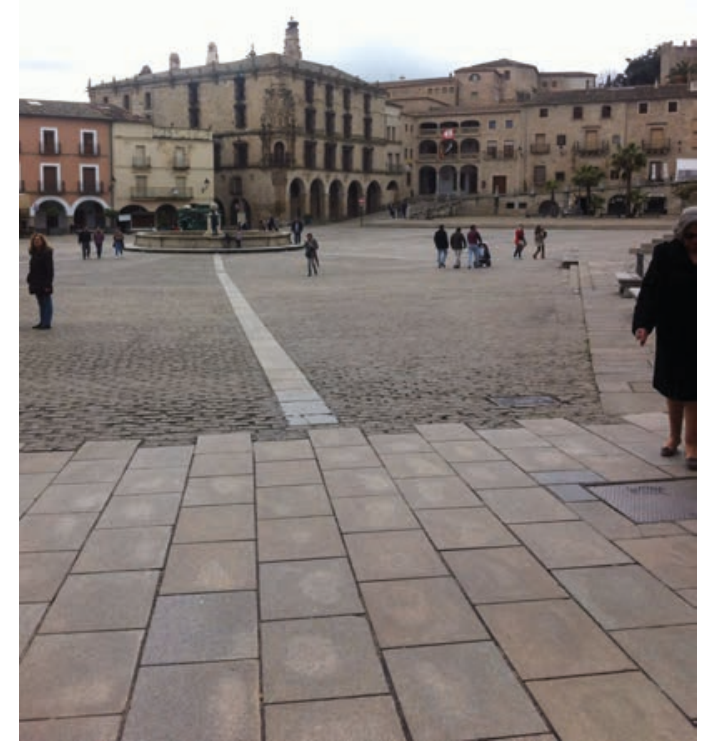

- Fig. 12. Vista general de la plaza desde San Martín en marzo de 2017. Foto de Alfonso Cardenal. 
ción de la Plaza Mayor llevado a cabo por la Dirección General de Arquitectura a lo largo de la década de los sesenta. Si bien fue esta última la que ejerció un papel determinante para la fijación de una imagen de la plaza y todos sus frentes gracias al mantenimiento de los criterios de intervención de la primera.

\section{BIBLIOGRAFÍA}

ALMARCHA NÚÑEZ-HERRADOR, E., "Recuperar la esencia. El Corral de Comedias y Almagro", en P. MARTÍNEZBURGOS GARCÍA y M. E. SAÍNZ MAGAÑA (coords.), El Greco en su IV Centenario: patrimonio hispánico y diálogo intercultural, Toledo, 2016, pp. 377-400.

BARRERO RODRÍGUEZ, C., La ordenación jurídica del patrimonio histórico, Madrid, 1990.

CASES GÓMEZ DE OLMEDO, S., Fuentes documentales para el estudio de la restauración de monumentos en España, Madrid, 1989.

CASTILLO RUIZ, J., El entorno de los bienes inmuebles de interés cultural, Granada, 1997.

"Las instrucciones para la defensa de los conjuntos histórico-artísticos: el inicio de la moderna protección de la ciudad histórica en nuestro país", Cuadernos de Arte, no 27, 1996, pp. 241-254.

FERNÁNDEZ MUÑOZ, Y., "Evolución y restauraciones sufridas en el castillo de Trujillo en el siglo XX", Norba Arte, XXXXI, 2000-2001, pp. 149-162.

GARCÍA CUETOS, M. P., “La Imperial Tarraco. Restauración de los testimonios de la Tarragona romana bajo el franquismo", De Arte. Revista de Historia del Arte, no 13, 2014, pp. 263-286.

GARCÍA CUETOS, M. P., ALMARCHA NÚÑEZ-HERRADOR, E. y HERNÁNDEZ MARTÍNEZ, A. (coords), España e
Italia ante la recuperación monumental de posguerra, Gijón, 2010.

Historia, restauración y reconstrucción monumental en la posguerra española, Madrid, 2012.

HERNÁNDEZ MARTÍNEZ, A. y CASTRO FERNÁNDEZ, B., "Patrimonio monumental y turismo. La ordenación de conjuntos monumentales en Aragón: el caso de Sos del Rey Católico (Zaragoza)", erph, no 13, 2013, pp. 79-117.

Mapa del Patrimonio Histórico Inmueble, Tomo I-Bienes de Interés Cultural, Madrid, 1995.

MÉLIDA ALINARI, J. R., Catálogo monumental y artístico de la provincia de Cáceres (1914-1916), Vol. 2, Madrid, 1924.

MOGOLLÓN CANO-CORTÉS, M. P., La restauración monumental durante la posguerra en Extremadura y la Dirección General de Bellas Artes 1940-1958, Cáceres, 2011.

"La fiel restauración en las intervenciones de González Valcárcel: aproximación a la práctica restauradora del arquitecto en la España franquista", en J. DELGADO RODRIGUES (coord.), De Viollet le Duc a Carta de Veneza, Lisboa, 2014, pp. 47-54.

"La fachada del santuario del Monasterio de Guadalupe y su restauración", en M. A. ZALAMA RODRIGUEZ y M. P. MOGOLLÓN CANO-CORTÉS, Alma Ars. Estudios de arte e iconografía en homenaje al Dr. Salvador Andrés Ordax, Valladolid 2013, pp. 335-340.

MORAIS VALLEJO, E., "Traslado de edificios históricos. El caso de León durante la etapa franquista", De Arte, oㅡ 1, 2002, pp. 113-137.

MORENO GARRIDO, A., Historia del turismo en España en el siglo XX, Madrid, 2010.

ORDOÑEZ VERGARA, J., "Restauración arquitectónica en la autarquía. La alcazaba de Málaga: entre la reconstrucción nacional y la escenografía historicista", en I. HENARES CUÉLLAR, J. CASTI- 
LLO RUIZ, G. PÉREZ ZALDUONDO y M. I. CABRERA GARCÍA (coords.), Dos décadas de cultura artística en el Franquismo (1936-1956), Granada, 2001, pp. 587-615.

PARDO FERNÁNDEZ, M. A., Un siglo de restauración monumental en los conjuntos históricos declarados de la provincia de Badajoz: 1900-2000, Cáceres, 2007.

"El arquitecto José Menéndez-Pidal y sus criterios de restauración monumental sobre los conjuntos histórico-artísticos", Laboratorio de Arte, XXV, 2013, pp. 799816.

"La ambientación de la ciudad histórica. Restauración monumental y urbana en los años sesenta", en M. A. ZALAMA RODRIGUEZ y M. P. MOGOLLÓN CANO-CORTÉS, Alma Ars. Estudios de arte e iconografía en homenaje al Dr. Salvador Andrés Ordax, Valladolid 2013, pp. 341-346.

"En dignas condiciones de presentación. José Menéndez-Pidal y la práctica de la restauración monumental en castillos y fortalezas de Extremadura", en J. DELGADO RODRIGUES (coord.), De Viollet le Duc a Carta de Veneza, Lisboa, 2014, pp. 39-46.

PERIS SÁNCHEZ, D., "Del monumento al patrimonio histórico. Caminos de la segunda mitad del siglo XX", en M. P. GARCÍA CUETOS, E. ALMARCHA NÚÑEZHERRADOR y A. HERNÁNDEZ MARTÍNEZ (coords.), Historia, restauración y reconstrucción monumental en la posguerra española, Madrid, 2012, pp 437-467.

PIZARRO GÓMEZ, F.J., Trujillo. Paisajes urbanos de Extremadura, Cáceres, 2007.

TENA FERNÁNDEZ, J., Trujillo Histórico y Monumental, Trujillo, 1966.

TORRES CAMACHO, N., "Suiza en la aventura de la Mancha: patrimonio y turismo cultural en los años del desarrollismo español", Cuadernos de Turismo, no 35, 2015, pp. 399-423. 